\title{
Assessment of myocardial perfusion-CMR in left main stem disease (LMS) in the CEMARC study
}

\author{
Arshad Zaman ${ }^{*}$, David L Buckley', Steven Sourbron', Neil Maredia², John F Younger ${ }^{2}$, Julia M Brown², \\ Jane Nixon ${ }^{3}$, Colin C Everett ${ }^{3}$, John P Ridgway ${ }^{1}$, Aleksandra Radjenovic ${ }^{1}$, Catherine J Dickinson ${ }^{4}$, Mark Sculpher ${ }^{5}$, \\ Steven G Ball ${ }^{2}$, John P Greenwood ${ }^{2}$, Sven Plein ${ }^{2}$
}

From 2011 SCMR/Euro CMR Joint Scientific Sessions

Nice, France. 3-6 February 2011

\section{Introduction}

Left main stem (LMS) disease is found in approximately $5 \%$ of patients with stable angina and in approximately $7 \%$ of patients presenting with an acute myocardial infarction. Accurate assessment of the degree of left main stem stenosis has important prognostic and therapeutic implications. Clinically, angiographic LMS stenosis of $50 \%$ or more is considered significant. However, it is not known how accurately myocardial perfusion imaging detects LMS disease at this severity threshold.

\section{Purpose}

1. To measure myocardial blood flow by CMR in patients with LMS stenosis of more than $50 \%$ on quantitative angiography in the CEMARC study (a large prospective evaluation of CMR against SPECT and coronary angiography ${ }^{1}$ ).

2. To correlate hyperaemic myocardial blood flow (MBF) and blood flow reserve between territories supplied by the LMS and remote territories.

\section{Methods}

Nine patients from the CEMARC study who were found to have significant LMS disease on quantitative coronary angiography underwent perfusion-CMR on a Philips $1.5 \mathrm{~T}$ Intera system. Myocaridal perfusion imaging was performed every heartbeat during the first pass of $0.05 \mathrm{mmol} /$ $\mathrm{kg}$ gadolinium chelate using a T1-weighted fast (spoiled) GE sequence. Stress perfusion imaging was performed using intravenous adenosine infused for 4 minutes $(140 \mathrm{mcg} / \mathrm{kg} / \mathrm{min})$. Perfusion-CMR data were post-processed off-line using the software $\mathrm{PMI}^{2}$. Following motion

${ }^{1}$ Medical Physics, Leeds, UK

Full list of author information is available at the end of the article

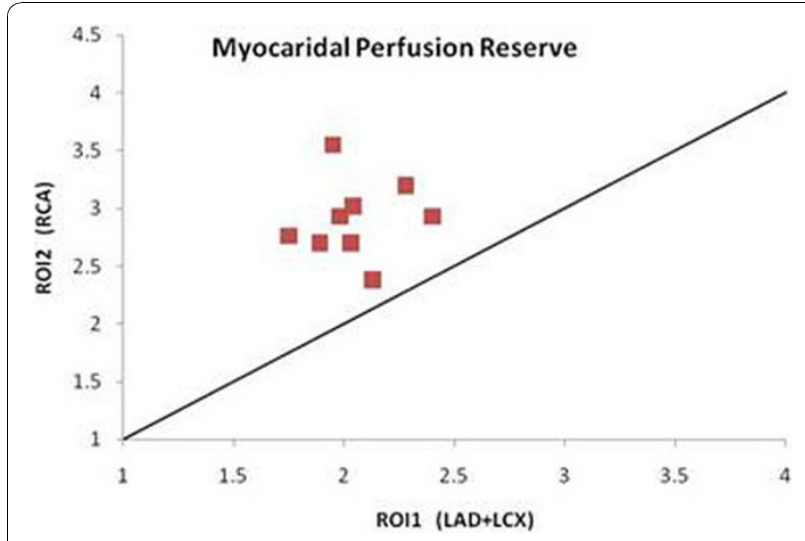

Figure 1 MPR values in LMS diseased terotories

correction a circular ROI was selected in the left ventricle to measure the arterial input function. MBF maps were created by model-free analysis; myocardial ROIs were drawn on these maps, one in the LMS territory (ROI1: $\mathrm{LAD}+\mathrm{LCX}$ ) and one in a remote region (ROI2:RCA). MBF for these ROIs was calculated using the Fermi model ${ }^{3}$. Statistical calculations were performed using SPSS.

\section{Results}

Of the 9 datasets analysed, the results revealed significant differences $(\mathrm{p}<0.001)$ in myocardial perfusion seen in LMS diseased territories (ROI1) compared to normal segments (ROI2), Figure 1. The mean myocardial perfusion reserve (MPR) of ROI1 was $2.05(\mathrm{SD} \pm 0.20)$ and for ROI2 $2.97( \pm 0.33)$.

\section{Conclusion}

This study demonstrates reduced myocardial blood flow reserve in patients with LMS stenosis of $50 \%$ or more, although reductions are subtle. 


\section{Author details}

${ }^{1}$ Medical Physics, Leeds, UK. ${ }^{2}$ Academic Unit of Cardiovascular Medicine,

Leeds, UK. ${ }^{3}$ Clinical Trials Research Unit, Leeds, UK. ${ }^{4}$ Department of Nuclear

Cardiology, Leeds, UK. ${ }^{5}$ Centre for Health Economics, York, UK.

Published: 2 February 2011

\section{References}

1. Greenwood, et al: 2009.

2. Sourbron, et al: 2009 .

3. Jerosch-Herold, et al: 1998.

doi:10.1186/1532-429X-13-S1-P170

Cite this article as: Zaman et al: Assessment of myocardial perfusion-

CMR in left main stem disease (LMS) in the CEMARC study. Journal of

Cardiovascular Magnetic Resonance 2011 13(Suppl 1):P170.

Submit your next manuscript to BioMed Central and take full advantage of:

- Convenient online submission

- Thorough peer review

- No space constraints or color figure charges

- Immediate publication on acceptance

- Inclusion in PubMed, CAS, Scopus and Google Scholar

- Research which is freely available for redistribution 